\title{
HYGIENE IN ELEMENTARY SCHOOLS, AND ITS BEARING ON HOME LIFE.
}

\author{
By ANNIE ROTHWELI, Cert.San.Inst. \\ Sanitary Inspector, Oldham.
}

\author{
(MeMber.) \\ ABSTRACT.
}

$\mathrm{M}^{\mathrm{r}}$

$Y$ reasons for offering this paper are two. First, that having myself

been a teacher in elementary schools both as assistant and head, I know the wonderful influence that teachers have over the children of the present day, who are to be our future citizens and parents of the future generation. Second, that now holding the position of Sanitary Inspector I see the great necessity of sanitary authorities obtaining the sympatly and aid of elementary school teachers to make the unhygienic homes of the population hygienic.

Therefore, what sanitary authorities require to do is to obtain this sympathy and aid of elementary school teachers, who will bring into action their well-known saying, "To get at the parent get at the child," thereby instructing at the same time both future parents and parents of to-day. When a child's interest is aroused in a subject it is certain to convey a portion of the instruction home. Take, for example, the boy who is receiving manual instruction, and the girl cookery and laundry lessons. Consider then what a child would do, at home, in the appliance of hygiene.

As regards the method of teaching this subject let it be practical, using the school for both illustration and experiment. Many people say it is useless to attempt the teaching of lygiene in a school not constructed on the best hygienic principles. Here ask this question: Are these children's homes built on the best hyorienic principles? No, far from it. What we are to do then is to teach the children how to make use of what appliances they have, comparing at the same the advantages of a home built on hygienic principles. The outcome of such teaching will be that future sanitary authorities will have to be on the alert, for these future parents and householders, as ratepayers, will not suffer their children to be reared in houses such as they had.

Now comos an important question: Should hygiene be made a special 
subject in the school course? Opinions may differ. But with what object is hygiene to be tanght in schools at all? Is it in order to obtain a good report from the inspector on the pupils' knowledge of the subject, accompanied with all its scientific terms? or, is it to obtain its practical appliance in their own homes? The latter certainly. If hygiene becomes a special subject, it must find a place on the school time-table and be subject to inspectors' reports. If such be the case, then it will become another burden to the already over-burdened elementary school teacher, and the true object of its teaching will be lost.

This does not mean that to give children of elementary schools a sufficient knowledge of practical lyggiene for their own homes it is necessary for them to have a knowledge of physiology, chemistry, and physics, in all their scientific terms. Hygiene can be taught in simple terms that can be understood by elementary school children.

Hygiene ought to be a home-training, but with the parents of to-day it cannot be. Let sanitary authorities obtain the help of school teachers, then hygiene will reach the homes of their scholars; it is certain. Who are more fitted to take up this so much needed branch of work than the teachers themselves, in whose care these children are for two thirds of a year, and for a period of at least eight years?

To avoid this teaching of hygiene becoming another burden to the teacher, special teachers of the subject may be appointed. These teachers would pay periodical visits to the schools, and give lectures on the subject. The schiool staff would then be only too willing to keep the information thus imparted always in the children's minds, and encourage its practical use at home.

The "Certificate of The Sanitary Institute for Hygiene" for such teachers stands high, and the course of training, held at Bedford College, London, is open only to certificated teachers, or to teachers having had two years' experience in secondary schools, which is a good proof that the teaching of liygiene must fall to the lot of school teachers if it is to reach the homes of the parents of to-day. 